control of ${ }^{14} \mathrm{C}$-sugar movement by changing the node temperature (J. A. Webb and P. R. Gorham), and dis. cussed the distinct lack of evidence demonstrating sugar conduction in the sieve tubes (D. C. Mortimer and M Suzuki). D. S. Fensom and D. C. Spanner (London, England) reported their measurements of microelectrode potentials in the conducting tissue of Nymphoides and Heracleum and calculated that the electro-osmotic efficiency was sufficient to maintain sugar flow through partially blocked siove plate pores.

In a final session on plant growth substances, several contributions were concerned with the influenco of exogenously supplied gibberellins and IAA on plant development. Three reports discussed tho interesting problems of IAA conjugation in plant tissues. E. Schneider and F. Wightman (Carleton, Ottawa) showed IAA $-2-{ }^{14} \mathrm{C}$ to be metabolized mainly through conjugation to indoleacetyl aspartic acid, indoleacetyl glucose and 2-OH indoleacetylglucose in barloy seedlings over a 24-h period. A. Winter and K. V. Thimann (Harvard University), however, could find no evidence for conjugate compounds over a 2 -h period in Avena coleoptiles and con- sidered fed ${ }^{14} \mathrm{C}$-IAA to be physically bound to a protein fraction. N. A. Andreae (Department of Agriculture London) showed that conjugate products were formed with IAA inactivation, when pea roots were pretreated with an excess of IAA and NAA. An adaptive period of 2-4 h was necessary before the conjugate products were discerned. 2,4-D was not conjugated and remained inhibitory regardless of the pretreatment time. J. I. Toohey and C. D. Nelson (Queens, Kingston) reported two new herbicides derived from a soil bacterium inhabiting old pastures. The compounds were toxic to algae and higher plants but not to insects, fish or mammals. They were isolated and identified as phenazine-1-carboxylic acid (most toxic to higher plants) and the 2-OH dorivative (most toxic to the algae).

Officers of the society elected for 1965-66 were: President, Dr. G. H. N. Towers (University of British Columbia); Vice-president, Dr. D. Simminovitch (Department of Agriculture, Ottawa); Secretary-treasurer, Dr. D. Canvin (Queens, Kingston); Eastern director, Dr. A. R. A. Taylor (University of New Brunswick); Western director, Dr. M. S. Spencer (University of Alberta). J. A. WEBB

\title{
A REGISTER OF SCIENTIFIC RESEARCH IN THE NETHERLANDS
}

$\mathrm{I}^{\mathrm{N}}$ N 1964 the Netherlands Organization for the Advancement of Pure Research (Z.W.O.) began a register of scientific research in the Netherlands. The results of this work are to be published in the form of a periodical guide giving details of current scientific investigations. The purpose of this guido is to foster contact between research scientists. It supplies both Dutch and foreign scientists with information on the research being carried out in the Netherlands. With the view of foreign readership it appears in English.

For recent scientific information the research scientist must depend either on personal contacts or on articles in journals, reports, otc. In the case of leading sciontists such as university professors working in small and highly specialized fields, personal contact often provides sufficient communication; however, this is much loss true of their staff. As regards research scientists in larger and above all multi-disciplinary fields, personal contact usually satisfies only a small part of the need for communication.

So far as journals, reports, etc., are concerned, not only does it take a long time until the original publications are reported in abstracting journals, but also there is a considerable interval before the results of a research project are published. Moreover, the research scientists concerned may have information available long before then. It may also be remarked that a great deal of research is never published, for a varioty of reasons, for examplo in the event of discontinuance of the project; valuable information may be lost in this way.

The marked expansion of research at the universities makes it still more desirable that the need for recent scientific information be satisfied. The guide contributes towards this by presenting research scientists with a basis on which further contacts can be established.

The guide has been inspired by the British publication Scientific Research in British Universities and Colleges, published by the Department of Scientific and Industrial Research and the British Council; this gives concise information on scientific research in Great Britain *

At first there was some doubt about the value of this publication in Britain, but in the course of the years its utility has been clearly proved. Consequently, Z.W.O. decided to build up experience by starting in one field and

* Now published by the Department of Education and Science and the British Council (Nature, 207, 691; 1965). submitting the result to scientists for discussion; physics was chosen as this first field.

In principle the guide only mentions research projects by or under the direct control of professors, lecturers and sciontific staff.

Taking into account the purpose of the guide, preference was givon to a main grouping by subject rather than by university department. As researeh scientists are best served by a classification that they already know, it was decided to follow the leading abstracting journal for each field of science. As the register is extended to more fields the disadvantage will have to be accepted of a certain lack of balance as compared with a general classification, such as the Universal Decimal Classification, which was dovised as a whole.

For physies, Physics Abstracts, published by the Institution of Electrical Engineers, London, has been chosen. The research seientist was asked to classify his research project under one of the ejghtoen headings of Physics Abstracts. In order to reduce discrepancies to a minimum, a copy of the classification followed by this journal was attached to the questionnaire.

In the guide the research projects are arranged under the afore-mentionod headings of Physics Abstracts. Within these groups there is a sub-division according to the institution where the research is being carried out. Besides a name index and a subject indox, a list of cooporating research institutes, with their addresses, is given.

Before questionnaires were sent out, the arrangement was submitted to the chairmen of the physics departments of tho various universities. The idea of this was to obtain their criticism in good time, so that allowance could be made for it in the questionnaire; most of them also proved ready to call on the co-operation of the professors and lecturers to be covered by the survey.

The questionnaire was kept simple so that filling it in would not take up too much of the scientist's time. Only those questions wore asked which are directly connected with the three questions which the guide trios to answer, namely: (1) What kind of research is being done? (2) Who is doing it ? (3) Where is it being done ?

To every professor and lecturer of physics were sent 5-10 questionnaires on which to report the relevant research; in most cases they wore sent direct, though in 
a few cases they went to a contact person for distribution to all the research scientists at a certain institution.

Although for practical reasons the first survey had to be confined to the universities, a small number of other bodies doing important physical research were also included in this first trial. Owing to the fact that investigations in borderline fields, such as physical chemistry and biophysics, are likewise done in non-physical laboratories, complete coverage was not entirely possible even within the universitios; it will, however, be approached as the registration progresses.

For rapid processing of the data received-particularly with the view of future expansion to more fields-mechanization is desirable. In the case of the first guide the procedure was as follows : The copy is typed in the order in which it is received on a 'Flexowriter' which produces a punched tape as well as a typoscript. After the copy has been completed the punched tape is read by a computer. This arranges the data for text and indexes in the desired order and records these on a new punched tape. The latter is then run through a 'Flexowriter' which types the manuscript for the printer without manual intervention. The pages are made up and reproduced in photo-offset.

In the preparation of the guide, Z.W.O. has received the assistance of the Statistics Department TNO for the mechanical processing of the copy and of the State Printing Department for printing. The title of the first publication, which has just appeared, is Current Research in the Netherlands, Physics, 1965 (Pp. 66. The Hague: Netherlands Organization for the Advancement of Pure Research (Z.W.O.), 1965). The guide for physics covers about 500 current research projects on which about 750 scientists are engaged. Institutions and research scientists can obtain this publication free of charge from the Dutch Embassy in their country, or direct from the Netherlands Organization for the Advancement of Pure Research (Z.W.O.), P.O. Box 2138, The Hague.

For the following issue of the register the choice has fallen on biology; this will be registered in co-operation with the Royal Netherlands Academy of Sciences. Other sciences will follow.

S. T. Groenman

\title{
OBSERVATIONS OF A STRONG UNIDENTIFIED MICROWAVE LINE AND OF EMISSION FROM THE OH MOLECULE
}

\author{
By Prof. HAROLD WEAVER, Dr. DAVID R. W. WILliaMS, Dr. N. H. DIETER and W. T. LUM \\ Radio Astronomy Laboratory, University of California, Berkeley
}

\begin{abstract}
$\Delta \mathrm{N}$ investigation of the galactic distribution of the A OH molecule as shown by the mierowave lines arising from transitions between the hyperfine levels of the ground state has led us to the following general conclusions: (1) The OH molecule is sharply confined to the galactic plane. In the plane, however, we detect $\mathrm{OH}$ in absorption in virtually every source brighter than a specifiable limit. (2) The $\mathrm{OH}$ molecule is in emission in some sources. (3) A strong unidentified emission line is present at frequency $1,665 \mathrm{Mc} / \mathrm{s}$ in a number of sources.
\end{abstract}

This discussion deals with the last two of these topies. We shall consider the galactic distribution of $\mathrm{OH}$ elsewhere.

Our observations were made with the 85 -ft. antenna and the 100-channel switched-frequency double-comparison receiver and digital data system recently installed at the Hat Creok Radio Observatory. This system, which will be described elsewhere in detail by one of us ${ }^{1}$, provides a spectrum consisting of 100 contiguous spectral elements which are either $10 \mathrm{kc} / \mathrm{s}$ or $2 \mathrm{kc} / \mathrm{s}$ wide. The band-width of the spectral elements is fixed by interchangeable crystal filters. The receiver includes a tunable parametric amplifier having a band-width of about $20 \mathrm{Mc} / \mathrm{s}$. The total system noise temperature (including instrumental effects such as spill-over and the like) is approximately $130^{\circ} \mathrm{K}$.

An 'observation', as the term will be used in this discussion, consists of the difference between the spectrum as observed for a specified source (integration time 1,600 sec) and the spectrum of a comparison region (integration time $1,600 \mathrm{sec})$ near the source but sufficiently far away so that the source is out of the antenna beam.

Observations of a strong unidentified microwave emission line. The Orion Nebula has been thoroughly searched for $\mathrm{OH}$ at $1,667 \mathrm{Mc} / \mathrm{s}$ by Robinson, Gardner, van Damme and Bolton ${ }^{2}$. They found no line and set an upper limit of 0.005 to the optical depth of $\mathrm{OH}$ in the direction of Orion. We concur with Robinson et al. that there is no observable line at $1,667 \mathrm{Mc} / \mathrm{s}$. However, our observations of Ori $A$ at 1,665 Mc/s show several emission components with a maximum antenna temperature of $3^{\circ} \mathrm{K}$ when the spectral resolution is $10 \mathrm{kc} / \mathrm{s}$ (Fig. 1 ).

W3, a bright extended $\mathrm{H}$ II region which we have also observed, shows, at $1,667 \mathrm{Mc} / \mathrm{s}$, an absorption component of $\mathrm{OH}$ with a depth of approximately $1^{\circ} \mathrm{K}$ (Fig. 1). At $1,665 \mathrm{Mc} / \mathrm{s}$ we find, as would be predictable, the second strongest $\mathrm{OH}$ microwave line arising from the ground state. The depth of the 1,665 line, again as predicted, is about $0.5^{\circ} \mathrm{K}$. At $1,612 \mathrm{Mc} / \mathrm{s}$ there is no absorption feature visible (Fig. 1) in the one observation we were able to make before this investigation ended. Our single observation is inadequate to show the expected OH feature at $1,612 \mathrm{Mc} / \mathrm{s}$ (predicted depth $\sim 0.1^{\circ} \mathrm{K}$ ), but it is adequate to demonstrate that there are no large anomalies at $1,612 \mathrm{Mc} / \mathrm{s}$. The outstanding feature of these three spectral regions is the intense emission feature (maximum antenna temperature $8.2^{\circ} \mathrm{K}$ for $10-\mathrm{kc} / \mathrm{s}$ spectral resolution)

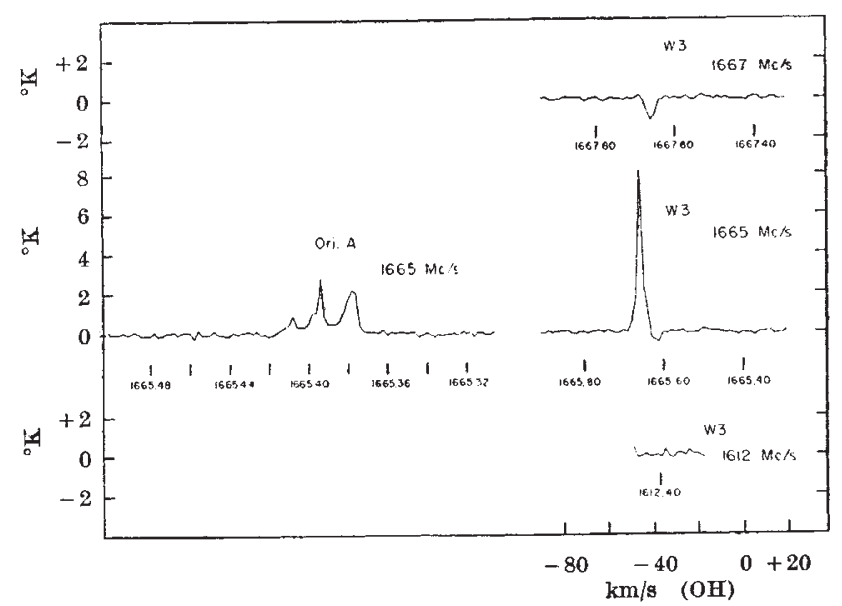

Fig. 1. Spectra of Ori $A$ and $W 3$ with a resolution of $10 \mathrm{kc} / \mathrm{s}(1.8 \mathrm{~km} / \mathrm{sec})$. Frequeney and velocity scales are with respect to the local standard of rest. The frequencies in the $1,667 \mathrm{Mc} / \mathrm{s}$ spectrum of $W 3$ should be decreased by $0 \cdot 10 \mathrm{Mc} / \mathrm{s}$. Those in ori $A$ should read $1,665 \cdot 80, \cdot 60,40$, $\cdot 20, \cdot 00$. The ordinate is antenna temperature 